\title{
Evolution of symptoms with antipsychotic treatment in schizophrenic outpatients in Greece: the GRACE Study
}

\author{
Dimitra Karadima ${ }^{1 *}$, Ioannis Chatzimanolis ${ }^{2}$, Errikos Tsebelikos ${ }^{3}$, Venetsanos Mavreas ${ }^{4}$, Athanasios Fokas ${ }^{5}$, \\ Athanasios Kalogeropoulos ${ }^{6}$, Simeon Deres ${ }^{7}$, Theodosios Christodoulakis ${ }^{8}$ \\ From $1^{\text {st }}$ International Congress on Neurobiology and Clinical Psychopharmacology and European \\ Psychiatric Association Conference on Treatment Guidance \\ Thessaloniki, Greece. 19-22 November 2009
}

\section{Background}

To describe positive, negative and other symptoms evolution following treatment change, in schizophrenic patients in Greece.

\section{Materials and methods}

The GRACE study was a non-interventional observational, multicentre national survey. It involved 104 centres, proportionally distributed over Greece and observed patients diagnosed and treated for schizophrenia in the outpatients setting over a period of 12 months spanning from June 2007 till June 2008. Demographic and other patient characteristics including family status, educational level, living status, employment status, and centres monitoring patient's condition were recorded. Positive (aggressive behaviour, disorganised speech/ thinking, illusions, delusions), negative (affective flattening, blunted effect, avolition, social isolation) and other (affective symptoms, aggressiveness, sleep disorders, cognitive disorders) symptom changes were recorded and analysed prior and post treatment change. Statistical analysis was performed by McNemar's Chi square statistic.

\section{Results}

In total, 2013 patients, mean age $39.7 \pm 12.5$, were included in the study, $54.4 \%$ of which were males and $45.6 \%$ females. Most of the patients were unmarried (64\%), living with their family (64.4\%) and unemployed $(54.2 \%)$ at the time of screening. After treatment change to another antipsychotic agent positive symptoms

${ }^{1}$ Bristol - Myers Squibb, Greece significantly decreased by $23.6 \%(\mathrm{p}<0.005)$, negative symptoms remained unchanged and other symptoms significantly decreased by $15.9 \%(\mathrm{p}<0.05)$. Illusions, delusions and disorganised speech/thinking, were the positive symptoms with the most profound decrease $(14 \% \mathrm{p}<0.001,13.1 \% \mathrm{p}<0.001$ and $5.4 \% \mathrm{p}<0.005$ respectively). No significant changes were observed in affective flattening, aggressiveness, sleep and cognitive disorders. All administered antipsychotic treatments were associated with significant decrease in positive symptoms, with ziprasidone, olanzapine, rispesridone, quetiapine, aripiprazole, and aminosulpride showing more than $20 \%$ decrease $(\mathrm{p}<0.001)$. Ziprasidone, aripiprazole, cloazapine, quetiapine and aminisulrpide were associated with decrease in negative treatments, however only ziprasidone and ariprazole decreases reached significance $(\mathrm{p}<0.01$ and $\mathrm{p}<0.02$ respectively. All agents, showed significant decrease in other symptoms $(\mathrm{p}<$ 0.001).

\section{Conclusions}

Negative symptoms remain difficult to control showing inconsistent patterns of symptom responsiveness. Currently available second generation antipsychotic agents appear to have minor to modest benefits on negative symptoms. All administered antipsychotics seem to have equal effectiveness in suppressing positive symptoms presented by schizophrenic patients in Greece.

\footnotetext{
Author details

${ }^{1}$ Bristol - Myers Squibb, Greece. ${ }^{2}$ Department of Psychiatry, University Hospital "Eginition", Athens, Greece. 30partment of Psychiatry,

"Sismanogleion" Hospital, Athens, Greece. ${ }^{4}$ Department of Psychiatry,
} 
University Hospital, Ioannina, Greece. ${ }^{5}$ 2nd Department of Psychiatry, Hospital "Papageorgiou", Thessaloniki, Greece. ${ }^{6}$ Hospital "Agia Fotini", Larissa, Greece. ${ }^{7}$ Hospital "Therapeutirio Asklipios ", Veria, Greece. ${ }^{8}$ Hospital "Panagia Grigorousa", Athens, Greece.

Published: 22 April 2010

doi:10.1186/1744-859X-9-S1-S93

Cite this article as: Karadima et al: Evolution of symptoms with antipsychotic treatment in schizophrenic outpatients in Greece: the GRACE Study. Annals of General Psychiatry 2010 9(Suppl 1):S93.

Submit your next manuscript to BioMed Central and take full advantage of:

- Convenient online submission

- Thorough peer review

- No space constraints or color figure charges

- Immediate publication on acceptance

- Inclusion in PubMed, CAS, Scopus and Google Scholar

- Research which is freely available for redistribution

Submit your manuscript at www.biomedcentral.com/submit 